\title{
Literatura rebelde zapatista: a produção e a escrita do subcomandante insurgente Marcos
}

\section{Zapatista rebel literature: the production and the writings of the insurgent subcomandante Marcos}

\author{
Marcela Araújo Vitali ${ }^{1}$
}

\begin{abstract}
Resumo
Este artigo tem como objetivo apresentar algumas considerações acerca da produção literária do subcomandante insurgente Marcos, membro militar e político do denominado movimento zapatista, ou EZLN (Exército Zapatista de Libertação Nacional). Além das participações ativas no referido movimento, desde sua aparição pública no estado mexicano de Chiapas, em 1994, o subcomandante exerceu habilidades literárias no campo da criação textual e discursiva. Dessa forma, entendemos sua produção como parte integrante da comunicação oficial do EZLN, que em forma de histórias, contos e personagens se integrou aos comunicados zapatistas. Entre suas produções, analisaremos Los arroyos cuando bajan, Los zapatistas no se rinden e La historia de la noche y las estrellas. Nestas, seu personagem principal é representado pelo ancião indígena Velho Antônio, que mantém forte interlocução com o subcomandante, enriquecendo assim sua produção. A partir dessa análise, demonstraremos as operacionalizações guiadas por sua produção literária, tais como a legitimação de discursos políticos e a tentativa de representação étnica. A metodologia utilizada será a denominada Análise Crítica do Discurso; realizaremos as análises a partir de uma concepção inter-relacional entre criação e contexto, no que diz respeito à produção e publicação dos documentos.
\end{abstract}

Palavras-chave: subcomandante Marcos; Velho Antônio; literatura zapatista; discursos zapatistas; EZLN.

\begin{abstract}
This article aims to present some considerations about the literary production of the insurgent Subcomandante Marcos, military and political member of the Zapatista movement called EZLN (Zapatista Army of National Liberation). In addition to active participation in that movement, since its public appearance in the Mexican state of Chiapas, in 1994, Subcomandante exercised literary skills in the field of textual and discursive creation. Thus, we understand its production as part of the official communication of the EZLN, that make stories, tales and how the characters have joined to the zapatista reports. Among his productions will analyze La historia de los hombres y las mujeres de maíz, Los zapatistas no se rinden and La historia de los otros. In all of them, your main character is represented by

\footnotetext{
1 Mestre em História pelo Programa de Pós-Graduação em História Social das Relações Políticas da Universidade Federal do Espírito Santo (UFES). Título da pesquisa: A identidade étnica indígena no discurso político do movimento zapatista: a voz do Viejo Antonio (1994-1998). E-mail: m-vitali @ hotmail.com
}

\section{GANPHLAC}

Revista Eletrônica da ANPHLAC, ISSN 1679-1061, Nº 17, p. 189-213, jul./dez. 2014. http://revista.anphlac.org.br/ 
indigenous elder Old Antonio, which maintains strong dialogue with the Subcomandante, thus enriching their production. From this analysis we try demonstrate the operationalization guided by his writing, such as the legitimacy of political speeches and attempting to ethnic representation. The methodology used is the so-called Critical Discourse Analysis; we will make the analysis from an interrelation between production and context, specifically the production and publication of the documents.

Keywords: Subcomandante Marcos; Old Antonio; zapatism literature; zapatism speech; EZLN.

Artigo recebido em: 31/08/2014

Artigo aprovado para publicação em: 28/11/2014

A aparição pública do movimento zapatista no dia 1ำ de janeiro de 1994 possibilitou aos seus expectadores o conhecimento, mesmo que conciso, sobre o movimento que há anos gestava-se nas montanhas da Selva Lacandona, junto às diversas etnias indígenas ${ }^{2}$ que ali viviam. Durante sua ação militar ${ }^{3}$, o Exército Zapatista de Libertação Nacional realizou seu primeiro contato discursivo com a sociedade civil e o governo mexicano, por meio do comunicado intitulado Primeira Declaración de La Selva Lacandona (EZLN, 1994, p. 33-35). Esse documento nos trouxe informações iniciais acerca desse movimento que se levantara em armas. Com seu primeiro material discursivo, os zapatistas, pelas palavras e frases do comunicado, "falaram" aos mexicanos sobre suas origens, explicaram os motivos do levante armado e suas demandas ${ }^{4}$, mesmo que brevemente.

Após a divulgação do comunicado, os zapatistas continuaram a publicar outros documentos, com o intuito de informar o público sobre os principais acontecimentos que circundavam o estado de Chiapas. Além disso, os comunicados divulgados no ano de 1994 foram direcionados a instâncias da sociedade civil, órgãos do governo e a outros movimentos sociais e indígenas. Recorremos a essa declaração para mostrar que, desde o princípio de sua aparição, os zapatistas apoiaram-se na ação discursiva e no uso das palavras, não somente

\footnotetext{
${ }^{2}$ As principais etnias que representam as bases sociais e políticas do movimento zapatista são tzotzil, tzeltal, tojolabal, chol, mam, lacandones, entre outros.

${ }^{3}$ A primeira ação militar dos rebeldes diz respeito à ocupação de alguns municípios chiapanecos pelos zapatistas e aos enfrentamentos com o Exército Federal.

${ }^{4}$ As demandas levantadas pelos zapatistas em 1994, tais como terra, alimentação, justiça, democracia e paz, já haviam sido reivindicadas no Congresso Indígena de Chiapas, em 1974.
}

\section{GANPHLAC}

Revista Eletrônica da ANPHLAC, ISSN 1679-1061, N. 17, p. 189-213, jul./dez. 2014. http://revista.anphlac.org.br/ 
para informar, mas também com o intuito de fazer da prática um instrumento de enfrentamento e resistência política.

Os periódicos assumiram a primeira forma de comunicação adotada, mas outro meio também foi ganhando espaço, nas semanas seguintes ao levante: a internet. $\mathrm{O}$ uso desse suporte, em primeiro lugar, se deu a partir da organização das redes de solidariedade que foram se formando no México e ao redor do mundo. Os comunicados começaram a circular na rede, sendo traduzidos para diversas línguas, ao mesmo tempo em que angariavam mais apoiadores ou críticos para o movimento zapatista. A primeira página de apoio aos zapatistas foi criada nos EUA pelo professor da Universidade da Califórnia, Justin Paulson, sob o nome Ya basta! (FUENTES SÁNCHEZ, 2012, p. 19).

Os documentos emitidos pelo EZLN convertem-se em fontes e são utilizados neste artigo como obras primárias. Entendemos que estas foram produzidas em determinados contextos políticos e sociais que derivaram de situações enfrentadas pelo EZLN. Logo, apresentam-se como representações produzidas pelos zapatistas e que estão atreladas ao meio; além disso, são responsáveis pela formação e caracterização do discurso do movimento (CARDOSO; VAINFAS; 1997, p. 378). Porém, antes de analisá-los, devemos ter em conta algumas considerações importantes acerca de suas estruturas e criadores.

Os comunicados zapatistas apresentam-se, na grande maioria, em forma de cartas, possuem destinatários e interlocutores - ao povo do México, a um representante político, a um partido, crianças, mulheres, intelectuais etc. -, apresentam datas, local de origem, além de virem acompanhadas de posdatas $^{5}$. Estas últimas são inclusões do subcomandante Marcos, que, a partir delas, expõe seus textos, que podem configurar-se em distintas formas discursivas, tais como contos, poemas, relatos e alegorias. O gênero epistolar, que caracteriza os documentos, possibilita a ideia de construção de possíveis diálogos entre os zapatistas e aqueles que os leem, também torna possível o recebimento de opiniões alheias, como se a construção comunicativa e de demandas fosse contínua.

A voz criadora e discursiva do EZLN pode ser representada pelo CCRI-CG (Comitê Clandestino Revolucionário Indígena - Comandância Geral) ${ }^{6}$, formado majoritariamente por

\footnotetext{
${ }^{5}$ Em português, "pós-escrito"; dá a noção de destaque a alguma ideia que se queria lembrar ao final do texto.

${ }^{6}$ O CCRI-CG, além de função comunicacional, também representa uma das estruturas políticas do EZLN. Composto por 12 membros, estes representam as etnias indígenas que formam as bases do movimento, como tzeltal, tzotzil, zoque, tojolabal, chol e mam (MOLINA, 2000, p. 211).
}

\section{GANPHLAC}

Revista Eletrônica da ANPHLAC, ISSN 1679-1061, №. 17, p. 189-213, jul./dez. 2014. http://revista.anphlac.org.br/ 
indígenas que compõem as regiões chiapanecas onde o zapatismo se formou e atua e, entre eles, temos homens e mulheres. O surgimento desse órgão remonta ao ano de 1992, quando os membros do EZLN planejavam sua participação política nos eventos comemorativos dos 500 anos da América em Chiapas e em 1993, quando as bases do movimento reuniram-se novamente para acertar o eventual levante público que iriam realizar no ano seguinte, em 1994.

Desde a sublevação, conhecemos a voz emitida por esse órgão, pois todos os comunicados oficiais que remetiam aos primeiros eventos e ao EZLN vieram assinados por ele. Em um documento do dia 11 de janeiro de 1994, os zapatistas também afirmaram que não aceitariam que a voz indígena fosse apresentada por aqueles que não os representassem e que só poderiam falar em nome dos rebeldes aqueles que assim fossem autorizados. O documento nos mostra que a mediação e representatividade em nome do zapatismo apenas se realizariam a partir da autorização e aprovação de seus membros. Dessa forma:

[...] rechazamos también cualquier otra propuesta o auto propuesta de tomar nuestra voz y nuestra palabra, nuestra voz empezó a caminar desde siglos y no se apagará nunca más. En cambio, saludamos y recibimos bien todos los intentos y propuestas, hechas de buena fe y con honestidad, de intermediación entre este EZLN y el gobierno federal (EZLN, 1994, p. 79).

Nesse sentido, percebemos que, além do CCRI-CG, também é possível identificar a enunciação da voz indígena zapatista a partir de seus mediadores, ou como os próprios denominam, a partir de seus "porta-vozes". Desde 1994, alguns membros do movimento destacaram-se nessa função, como o subcomandante ${ }^{7}$ Marcos, os comandantes Moisés e Tacho e as comandantes Ramona e Ana María. Sabemos que a escolha e nomeação dos “porta-vozes" zapatistas atendem, principalmente, a critérios de estratégia política e tentam não se basear em padrões de favoritismo (BERGHE, 2005, p. 69). A função destes seria a de transmitir, em nome do zapatismo, as mensagens e informações que lhes foram passadas pelo CCRI-CG.

\footnotetext{
${ }^{7}$ O termo "subcomandante" nas estruturas militares e políticas do EZLN faz referência a Marcos, que, entre todos, é o representante não indígena do movimento. Daí que sua posição de "sub" representa certa subordinação aos demais membros do movimento, que são majoritariamente indígenas. Estes, por sua vez, seguem a nomenclatura "comandante".
}

\section{GANPHLAC}

Revista Eletrônica da ANPHLAC, ISSN 1679-1061, No. 17, p. 189-213, jul./dez. 2014. http://revista.anphlac.org.br/ 


\section{A voz do subcomandante Marcos no discurso zapatista}

Entre os "porta-vozes" zapatistas, aquele que se sobressaiu, a partir de 1994, foi o subcomandante insurgente Marcos. Membro militar e político do movimento, o subcomandante começou a ganhar visibilidade a partir das primeiras tentativas de diálogo realizadas entre o EZLN e o Estado mexicano nos primeiros meses após a sublevação, na Catedral de San Cristóbal de las Casas, em Chiapas. Porém, antes mesmo do referido contexto, o CCRI-CG havia declarado que só seriam aceitos como documentos oficiais zapatistas aqueles que viessem firmados pelo órgão e pelo subcomandante. Com isso, fica claro que o próprio movimento dá a Marcos sua parcela de importância na ação discursiva zapatista (EZLN, 1994, p. 79).

No prólogo do livro Relatos de el Viejo Antonio: subcomandante insurgente Marcos, Armando Bartra (1998, p. 7-17) relata o mito tzotzil sobre o roubo de um livro indígena por um mestiço que se autodenominava conhecedor de toda a sabedoria, por isso o livro deveria estar em suas mãos; por sua vez, o objeto roubado representava a palavra indígena, personificada no livro. Bartra conta a história para fazer alusão ao esquecimento histórico, ao qual tantas comunidades indígenas do México estiveram sujeitadas. Afirma que "as palavras indígenas" roubadas só foram devolvidas anos mais tarde, por outro mestiço, em 1994:

Y la voz de los mayas chiapanecos susurraba su mensaje en libros, folletos y periódicos, pero sólo fue escuchada por todos cuando se hizo acompañar por el tronido de las armas. "El libro" regresó, en verdad, a manos de los tzotziles el primero de enero de 1994, día en que nos amanecemos con el conque de que los indios acababan de tomar Ciudad Real y gracias a ello habían tomado también la palabra. (BARTRA, 1998, p. 10)

Na história citada, o subcomandante Marcos é o "tradutor" das palavras indígenas ao mundo exterior, ao mundo ocidental. Contudo, a função do mestiço não se baseia apenas na simples tradução da língua tradicional ao espanhol, mas vai além (BERGHE, 2005, p. 63). Como exemplifica Bartra, o trabalho de Marcos significou uma tradução de elementos concernentes a mundos distintos, às vezes tão difíceis de serem compreendidas por seus receptores. Os próprios zapatistas afirmam que o subcomandante Marcos assumiu a função de "porta-voz" com o intuito de levar a mensagem dos rebeldes ao público externo e que assim deveria ser compreendida. Dessa forma, haveria uma divisão de trabalho consentida nas

\section{GANPHLAC}

Revista Eletrônica da ANPHLAC, ISSN 1679-1061, N. 17, p. 189-213, jul./dez. 2014. http://revista.anphlac.org.br/ 
estruturas políticas e comunicacionais do EZLN, refletida em suas bases e em seus "portavozes", que devem falar em nome da coletividade (BERGHE, 2005, p. 62-63).

Além da função apresentada, Marcos também desenvolveu habilidades discursivas que vieram acompanhadas de produções firmadas junto ao CCRI-CG, sendo assim parte integrante do discurso zapatista. Seu primeiro texto foi publicado em 27 de janeiro de 1994, em Chiapas: el Sureste en dos vientos, una tormenta y una profecia (EZLN, 1994, p. 49-66). O texto havia sido escrito em 1992 e buscava apresentar aos mexicanos as considerações indígenas acerca das condições políticas, econômicas e sociais do estado de Chiapas. Jan de Vos (VOS, 2002, p. 325) nos indica que o texto foi utilizado por Marcos em cursos de história e análise política, ministrados entre os militantes do EZLN, e também serviu de instrumento de preparação para o levante que se realizaria dois anos depois.

A partir de então, alguns intelectuais ${ }^{8}$ se debruçaram sobre a produção de Marcos com o intuito de analisar e caracterizar seu trabalho, ou até mesmo de aproximar ou distanciá-lo do discurso zapatista. Houve quem, de forma entusiasmada, o denominou como "el mejor escritor latino-americano de nuestros días, el más modernista, el más libre, el de mayor repercusión” (DEBRAY, 1995, p. 49). Ou aqueles que o acusaram de um tradicionalismo revolucionário que, "por debajo del lenguaje fresco [...] sigue supurando la intransigência de los viejos activistas de los años setenta” (DE LA GRANGE; RICO; 1997, p. 367). Porém, o que mais chamou a atenção dos críticos talvez tenha sido a multiplicidade de temas abordados em seus textos, o que caracterizaria um estilo de escrita "plurigenérica" - onde política, economia, aspectos sociais e étnicos eram apresentados (PELLICER, 1996, p. 199-208).

Para a pesquisadora Kristine Vanden Berghe, não foi somente a produção textual de Marcos que ganhou destaque junto aos zapatistas; o próprio subcomandante assumiu certo papel protagônico discursivo dentro do movimento, provocando dúvidas em relação à mediação e representatividade exercida nas estruturas do EZLN. Em sua pesquisa, aponta deslizes e conflitos entre as vozes discursivas que representam o zapatismo, mas não retira de Marcos sua importância e nem o aponta como aquele que reduz a voz indígena ao segundo plano. Assim, defende que devemos analisar as vozes zapatistas separadamente para melhor compreensão, mas não devemos deixar de levar em conta que essas vozes agem em prol de

\footnotetext{
${ }^{8}$ Manuel Vásquez Montalbán; De la Grange e Maite Rico; Alejandro Raiter; José Rabasa etc.

\section{GANPHLAC}

Revista Eletrônica da ANPHLAC, ISSN 1679-1061, No. 17, p. 189-213, jul./dez. 2014. http://revista.anphlac.org.br/
} 
um objetivo político comum: a emancipação das etnias indígenas formadoras do zapatismo. Desse modo, Berghe propõe:

\begin{abstract}
En el contexto de una guerra que se libra en gran medida en los medios de comunicación y en la que el trabajo de la escritura constituye uno de los actos principales del drama, el que maneja las armas verbales no puede sino tener un gran poder y una enorme responsabilidad, inclusivo se escribe por encargo. Si en la teoría puede ser interesante distinguir entre las funciones de portavoz, traductor y dirigente, en el funcionamiento real de la guerrilla zapatista tales distinciones son probablemente menos relevantes de lo que puede aparecer (BERGHE, 2005, p. 69).
\end{abstract}

Em 1995 os zapatistas lançaram um comunicado que definia o papel de Marcos nas estruturas comunicacionais do movimento. O texto enfatizava que "el EZLN no es sólo Marcos" (EZLN, 1995, p. 332-339), mas que era também composto por "muchos compañeros igual o más capaces que Marcos para explicar nuestra lucha, para dirigir nuestro movimento y para mandar obedecendo" (EZLN, 1995, p. 332-339). Além disso, os próprios reconheceram que o subcomandante ganhara destaque nos meses iniciais ao conflito e seguia; porém, afirmaram que tentariam diminuir essa condição.

Entendemos também que o subcomandante possui autonomia autoral ${ }^{9}$ e o que escreveu a partir de 1994 foi resultado de sua formação pessoal e dos seus anos de experiência e sobrevivência junto às comunidades da Selva Lacandona, desde o início dos anos de 1980, quando os primeiros guerrilheiros formadores do EZLN chegaram à região. Daí torna-se importante ter em vista que a produção individual de Marcos representa a existência de um vasto material documental que nos leva a compreender outras características e estratégias do movimento zapatista que estão além das apresentadas nos comunicados oficiais.

Tendo em vista essas observações, entendemos que a voz do subcomandante está atrelada ao discurso zapatista, mesmo que, por muitas vezes, Marcos apresente criações individuais. Dessa forma, iremos analisar a produção textual de Marcos e, entre os diversos gêneros discursivos produzidos, vamos privilegiar os contos e relatos que foram publicados, em sua maioria, em forma de posdatas, junto ou não aos comunicados oficiais do CCRI-CG. Nossa investigação se dará em torno do personagem-protagonista de algumas dessas histórias,

\footnotetext{
${ }^{9}$ Além dos comunicados oficiais que assinou ao lado do CCRI-CG e dos textos produzidos individualmente em nome do zapatismo, há também produções autorais do subcomandante, como A $4^{a}$ guerra mundial já começou (1997); A história das cores (2003) e Mortos incômodos (2006).
}

\title{
CANPHLAC
}

Revista Eletrônica da ANPHLAC, ISSN 1679-1061, No. 17, p. 189-213, jul./dez. 2014. http://revista.anphlac.org.br/ 
denominado El Viejo Antonio $^{10}$, um ancião indígena que narra a Marcos aspectos da cosmovisão indígena maia.

\section{A produção literária do subcomandante Marcos: o Viejo Antonio}

Consideramos a produção literária do subcomandante Marcos, em grande medida, parte integrante do discurso político zapatista. Sabemos que essa produção, atrelada ao discurso dos rebeldes, pode ser exemplificada a partir do personagem denominado Velho Antonio, que teve sua primeira aparição nos escritos produzidos pelo subcomandante em 1994. Defendemos a hipótese de que o personagem criado por Marcos serviu para evidenciar certos acontecimentos políticos vivenciados pelos zapatistas, seja com o Estado mexicano, seja com a sociedade civil, assim como também apontar possíveis elementos pertencentes as identidades étnicas indígenas dos grupos indígenas de Chiapas que compõem o movimento. Dessa forma, além de representar acontecimentos inter-relacionais e afirmação identitária, o personagem também pôde representar a habilidade literária e criativa do subcomandante.

Nosso recorte temático, para a realização das análises dos documentos em questão, se concentrará entre os meses do ano de 1994. A razão da escolha foi o fato de acreditarmos ter sido esse primeiro ano de aparição pública do movimento zapatista um importante período de enunciação discursiva, do qual o subcomandante Marcos participou com suas produções literárias. Dessa forma, analisaremos algumas histórias que darão conta de exemplificar nossos principais objetivos neste artigo, tais como: Los arroyos cuando bajan (EZLN, 1994, I, p. 239-245), Los zapatistas no se rinden (EZLN, I, 1994, p. 267-268) e La historia de la noche y las estrellas (EZLN, 1994, I, p. 88-91).

Nosso objetivo principal diz respeito à exemplificação das operacionalizações políticas dos discursos zapatistas. Para atendê-lo, demonstraremos como a produção discursiva e literária do subcomandante Marcos tornou-se importante nesse contexto, a partir da publicação de histórias e contos em que diversos aspectos concernentes às identidades étnicas indígenas são levantados. Entendemos que, em contextos inter-relacionais, como os

\footnotetext{
${ }^{10}$ Além do Viejo Antonio, outro personagem que aparece em muitas das histórias escritas pelo subcomandante Marcos é o Don Durito de la Lacandona. Este seria um escaravelho que conversava com Marcos acerca de neoliberalismo, política e economia mexicana. As histórias entre Marcos e Don Durito, além de terem sido publicadas juntamente a alguns dos comunicados oficiais do EZLN, desde 1994, ganharam uma compilação produzida pelo Cento de Investigação e Análise de Chiapas (CIACH), em 1998.
}

\section{GANPHLAC}

Revista Eletrônica da ANPHLAC, ISSN 1679-1061, N. 17, p. 189-213, jul./dez. 2014. http://revista.anphlac.org.br/ 
que serão analisados, o apontamento de aspectos relativos às identidades étnicas tornam-se instrumentos importantes do jogo e do combate político.

A manifestação das identidades étnicas, além de manifestação política, também pode ser considerada resultado do jogo de confrontações ou das relações interétnicas em que estão submetidas (OLIVEIRA, 1976, p. 47). Assim, a identidade étnica em ação pode afirmar-se e confrontar-se com o outro, num determinado contexto social ou político, podendo ser entendida como "etnicidade". A esse respeito, entre as distinções acerca do conceito de identidade étnica e etnicidade, Miguel Alberto Bartolomé nos diz:

Se puede apuntar que, dentro de las relaciones interétnicas, sería posible diferenciar la identidad o pertenecía al grupo étnico entendida como un fenómeno cognitivo, que nos permite identificarnos e identificar a los miembros de nuestro propio grupo, de la etnicidad concebida como un fenómeno del comportamiento, ya que supone conductas en tanto miembro de ese mismo grupo. La etnicidad puede así ser entendida como la identidad en acción resultante de una definida "conciencia para sí”. (ALBERTO BARTOLOMÉ, 2010, p. 62-63)

Para Poutignat e Streiff- Fenart, estudar a etnicidade significa compreender as ações produzidas pelas identidades étnicas em situações de contato e conflito; é identificar como esses grupos produzem e utilizam "marcas" que os tornam identificáveis e diferenciáveis dos outros. Além disso, é entender como manipulam certas "táticas e estratagemas" para se firmar ou se safar do jogo das relações interétnicas (POUTIGNAT; STREIFF-FENART, 2001, p. 117). Ao afirmamos isso, não estamos indicando o uso instrumental da etnicidade - que se baseia na organização dos grupos, em linhas étnicas, em prol do atendimento e conquista de objetivos comuns a pequeno ou médio prazo - mas, sim defendendo a ideia de que a manifestação da etnicidade serve a propósitos de resistência e emancipação. Logo, a manipulação da etnicidade pode ser historicizada e não somente submetida a processos contextuais (ALBERTO BARTOLOMÉ, 2010, p. 64-67).

Sobre as "táticas e estratagemas" utilizados pelas identidades étnicas nos contextos inter-relacionais, concordamos com a professora Manuela Carneiro da Cunha, que as denomina "sinais diacríticos" da identidade (CUNHA, 1986, p. 100-101). Nessa perspectiva, explica que as identidades étnicas em confronto irão se utilizar de sinais que as façam se opor ou se destacar em relação aos outros. Esta será construída a partir da seleção de elementos - à

\section{GANPHLAC}

Revista Eletrônica da ANPHLAC, ISSN 1679-1061, №. 17, p. 189-213, jul./dez. 2014. http://revista.anphlac.org.br/ 
escolha desses sujeitos - presentes na tradição do grupo e que passarão a assumir outra significação, dependendo dos novos usos e atributos que o grupo definirá. Assim, a escolha dos "sinais diacríticos" não é aleatória, tampouco sem sentido, pois assumem funções e significados que transbordam o político. Sobre as escolhas e seus usos, Carneiro da Cunha afirma:

[...] Vimos que a questão de saber quais os traços diacríticos que serão realçados para marcarem distinções depende das categorias comparáveis disponíveis na sociedade mais ampla, com as quais poderão se contrapor e organizar um sistema. Poderá ser a religião, poderão ser roupas características, línguas ou dialetos, ou muitas outras coisas. (CUNHA, 1986, p. 102)

Tendo os discursos zapatistas, mais precisamente as histórias escritas pelo subcomandante Marcos, como objeto de estudo, nossa metodologia de trabalho baseou-se na análise do discurso, a partir da Análise Crítica do Discurso (ACD), legado da escola francesa de análise do discurso e da linguística crítica (IÑIGUEZ, 2004, p. 118-120). Acreditamos que essa metodologia nos permitiu identificar o papel desempenhado pela produção literária do subcomandante Marcos, em seus contextos de produção e enunciação, sobretudo de forma crítica, pois, em contextos relacionais, analisar os textos criticamente nos permite identificar os elementos de inclusão ou exclusão, assim como as continuidades e rupturas que os enunciadores oferecem às suas produções.

Entendemos a produção literária e discursiva como prática social e integrada às estruturas que a produziram, que exerce papel fundamental na transformação ou manutenção das representações elaboradas, assim como nas relações de identidades entre os sujeitos e na sociedade. É também a partir dos textos que as lutas de representação são construídas e reelaboradas cotidianamente e levam seus enunciadores a firmar seus papéis políticos e se posicionar (PINTO, 2002, p. 18-20).

\section{Los arroyos cuando bajan}

No dia 28 de maio de 1994, o subcomandante Marcos publicou o primeiro texto em que aparece o Velho Antônio, como também publicou - inserido nesse texto - duas histórias contadas pelo ancião. Intitulado Los arroyos cuando bajan (EZLN, 1994, p. 239-245),

\section{GANPHLAC}

Revista Eletrônica da ANPHLAC, ISSN 1679-1061, Nº. 17, p. 189-213, jul./dez. 2014. http://revista.anphlac.org.br/ 
Marcos inicia apontando as dificuldades enfrentadas pelos zapatistas no que diz respeito à sobrevivência dos rebeldes nos municípios que haviam sido tomados, desde o $1^{\circ}$ de janeiro. Afirma que o principal obstáculo estava sendo lidar com os ataques constantes do Exército e a impossibilidade de arrecadar comida para as famílias que ocupavam as áreas. Assim o relatado por Marcos aponta essas primeiras impressões no espaço de resistência:

\begin{abstract}
Nosotros bien... cercados. Resistiendo "heroicamente" el vendaval de reacciones después del evento del 15 de mayo. A los vigilantes aviones ahora se suman, desde hace 3 días, helicópteros. Los cocineros se quejan de que no habrá ollas suficientes si se caen todos al mismo tiempo. El superintendente argumenta que hay suficiente leña para un asado, que por qué no invitamos a algún periodista argentino, que ésos saben hacer asados. (EZLN, 1994, p. 239)
\end{abstract}

Mais adiante, Marcos conta que começou a relatar a uma criança zapatista chamada Toñita, aquela que seria a primeira história que o Velho Antônio lhe contou e que assim diz: “[...] Toñita me pide un cuento. Le conto el cuento como me lo contó el viejo Antonio, el padre de aquel Antonio del viento que se levanta en 'Chiapas: el Sureste en dos ventos, una tormenta y una profecía"” (EZLN, 1994, p. 239).

O primeiro conto apresentado no documento indicado denomina-se La historia de los hombres y de las mujeres de maíz (EZLN, 1994, p. 239), em que o Velho Antônio relata a história de criação do mundo e dos homens e mulheres que nele vivem, retomando um passado de origem longínquo. Assim, segundo o ancião,

Cuando el mundo dormía y no se quería despertar, los grandes dioses hicieron su asamblea para tomar los acuerdos de los trabajos y entonces tomaron acuerdo de hacer el mundo y hacer los hombres y mujeres. Y llegó en la mayoría del pensamiento de los dioses de hacer el mundo y las personas. (EZLN, 1994, p. 239)

O fragmento nos mostra que, no princípio, o mundo fora criado e nele não havia quase nada, porém era necessário fazer com que esse mundo "funcionasse", e para isso era importante criar habitantes que pudessem trabalhar nele e o modificar. É possível perceber, também, a estimação que é dada à ação dos deuses no relato do ancião, demonstrando ainda a importância de se reunirem e de tomarem decisões conjuntas para o bem comum do mundo. Assim, continua Marcos relatando o que Antônio lhe contou:

[...] Y entonces pensaron de hacer las gentes y pensaran de hacerlas que fueran muy bonitas y que duraran mucho y entonces hicieron a las primeras gentes de oro $\mathrm{y}$

\title{
GANPHLAC
}

Revista Eletrônica da ANPHLAC, ISSN 1679-1061, Nº 17, p. 189-213, jul./dez. 2014. http://revista.anphlac.org.br/ 
quedaron contentos los dioses porque las gentes que hicieron eran brillantes y fletes. Pero entonces los dioses se dieron cuentan que las gentes de oro no se movían, estaban siempre sin caminar ni trabajar, porque estaban muy pesadas.

$\mathrm{Y}$ entonces se reunieron la comunidad de los dioses para sacar acuerdo de cómo van a resolver ese problema y entonces sacaron acuerdo de hacer otras gentes y las hicieron de madera y esas gentes tenían el color de la madera y trabajaban mucho y mucho caminaban y estaban otra vez contentos porque el hombre ya trabajaba y caminaba y ya se estaban de ir para echar alegría cuando se dieron cuenta que las gentes de oro estaban obligando a las gentes de madera a que las cargaran y les trabajaran.

$\mathrm{Y}$ entonces los dioses vieron que estaba mal lo que hicieron y entonces buscaran un buen acuerdo para remediar la situación y entonces tomaran acuerdo de hacer la gente de maíz, las gentes buenas, los hombres y mujeres verdaderos, viendo de remediar las cosas porque los dioses se fueron a dormir. Y la gente de maíz habló la lengua verdadera para hacer acuerdo entre ellas y se fueran a la montaña para ver de hacer camino para todas las gentes. (EZLN, 1994, p. 239-240)

Nesse conto é possível conhecer a história de criação do mundo e dos homens, assim como também voltar à história de criação expressa na tradição imaginária de origem maia précolombiana; esta última pode ser encontrada no denominado Popol $v u h^{11}$, livro que narra a história do povo maia-quiché. ${ }^{12}$ No relato do Velho Antônio, reconhecemos trechos que encontram semelhanças com as que se apresentam no livro, apesar das reformulações feitas por Marcos. Sobre a criação do mundo e de seus primeiros habitantes, o Popol vuh nos diz:

Ésta es la relación de como todo estaba en suspenso, todo en calma, en silencio; todo inmóvil, callado, y vacía la extensión del cielo. Ésta es la primera relación, el primer discurso. No había todavía un hombre, ni un animal, pájaros, peces, cangrejos, árboles, piedras, cuevas, barrancas, hierbas ni bosques: sólo el cielo existía. [...] Solamente había inmovilidad y silencia en la oscuridad, en la noche. Sólo el Creador, el Formador, Tepeu, Gucumatz, los Progenitores, estaban en el agua rodeados de claridade. [...] Llegó aquí entonces la palabra, vinieron juntos Tepeu y Gucumatz, en la oscuridad, en la noche, y hablaron entre sí Tepeu y Gucumatz. Hablaron, pues, consultando entre sí y meditando; se pusieron de acuerdo, juntaron sus palabras y su pensamiento. (RECINOS, 1960, p. 23)

Dessa forma, como contou o Velho Antônio a Marcos, o livro maia também relata a versão de que o mundo estava vazio e sem habitantes, no princípio, e que foi necessário os deuses se reunirem para decidir em coletivo o que seria feito desse mundo. Não havia animais, nem homens e mulheres, apenas os deuses, que sentiram a necessidade de habitar sua criação. Podemos apontar a hipótese de que Marcos se inspirou nesse livro para iniciar o

\footnotetext{
${ }^{11}$ O Popol vuh foi um livro escrito no século XVI e traz a narrativa acerca da criação do mundo, a partir da visão do povo maia. A expressão significa "livro da comunidade" ou "livro sagrado".

${ }^{12}$ Os maia-quinché representam uma das etnias maias localizada na região da Guatemala.
}

\section{GANPHLAC}

Revista Eletrônica da ANPHLAC, ISSN 1679-1061, N. 17, p. 189-213, jul./dez. 2014. http://revista.anphlac.org.br/ 
conto relatado pelo ancião, sendo que ambos apresentam versões próximas para o mesmo evento.

Outra semelhança entre ambos os documentos diz respeito à criação dos primeiros homens e mulheres para esse mundo. O Velho Antônio nos conta que estes foram criados pelos deuses primeiros na seguinte ordem: homens e mulheres de ouro, madeira e milho. Os primeiros eram muito pesados para trabalhar, por isso os deuses criaram os de madeira para exercerem essa função, todavia os últimos foram escravizados pelos de ouro. Dessa forma, a solução encontrada pelos deuses foi destruir esses homens e mulheres e criar aqueles que seriam chamados de "homens e mulheres verdadeiros", aqueles que foram feitos de milho, que, por sua vez, representam um alimento sagrado para os indígenas. Sobre essa criação, o livro dos maias-quiché nos relata uma versão um pouco diferenciada e com detalhes distintos, a saber:

Entonces fue ella creación y la formación. De tierra, de lodo hicieron la carne (del hombre). Pero vieron que no estaba bien, porque se deshacía, estaba blando, no tenía movimiento, no tenía fuerza, se caía, estaba aguado, no movía la cabeza, la cara se le iba para un lado, tenía velada la vista, no podía ver hacía atrás. Al principio hablaba, pero no tenía entendimiento. Rápidamente se humedeció dentro del agua y no pudo sostener. Y dijeron el Creador y el Formador. Bien se ve que no puede andar ni multiplicarse. Que se haga una consulta acerca de esto, dijeron. Entonces desbarataron y deshicieron su obra y su creación. Y en seguida dijeron: - ¿Cómo haremos para perfeccionar, para que salgan bien nuestros adoradores, nuestros invocadores?

[...]

En seguida les hablaron a aquellos adivinos, la abuela del día, la abuela del alba, que así eran llamados por el Creador y el Formador, y cuyos nombres eran Ixpiyacoc e Ixmucané. Y dijeron Huracán, Tepeu y Gucumatz cuando le hablaron algarero, al formador, que son los adivinos: - Hay que reunirse y encontrar los medios para que el hombre que formemos, el hombre que vamos a crear nos sostenga y alimente, nos invoque y se acuerde de nosotros.

- Entrad pues e consulta, abuela, abuelo, nuestra abuela, nuestro abuelo, Ixpiyacoc, Ixmucané, haced que aclare, que amanezca, que seamos invocados, que seamos adorados, que seamos recordados por el hombre creado, por el hombre formado, por el hombre mortal, haced que así se haga.

[...]

Y comenzado la adivinación, dijeron así: - ¡Juntaos, aclopaos! ¡Hablad, que os oigamos, decid, declarad si conviene que se junte la madera y que sea labrada por el Creador y el Formador, y si éste [ el hombre de madera ] es el que nos ha de sustentar y alimentar cuando aclare, cuando amanezca!

Tú, maíz, tú, tzité: tú, suerte; tú, criatura: ¡Ven a sacrificar aquí, Corazón del Cielo; no castigues a Tepeu y Gucimatz! Entonces hablaron y dijeron la verdad: - Buenos saldrán vuestros muñecos hechos de madera; hablarán y conversarán sobre la faz de la tierra. Y al instante fueron hechos los muñecos labrados en madera. Se parecían al hombre, hablaban como el hombre y poblaron la superficie de la tierra. [...] pero no

\section{GANPHLAC}

Revista Eletrônica da ANPHLAC, ISSN 1679-1061, Nº 17, p. 189-213, jul./dez. 2014. http://revista.anphlac.org.br/ 
tenían alma, ni entendimiento, no se acordaban de su Creador, de su Formador; caminaban sin rumbo y andaban a gatas. [...] En seguida fueron aniquilados, destruidos y deshechos los muñecos de palo, y recibieron la muerte.

[...]

He aquí, pues, el principio de cuando se dispuso hacer el hombre, y cuando se buscó lo que debía entrar en la carne del hombre. [...] Se juntaron, llegaron y celebraron consejo en la oscuridad y en la noche; luego buscaron y discutieron, y aquí reflexionaran y pensaron. [...] y encontraron y descubrieron lo que debía entrar en la carne del hombre. [...] Y así encontraron la comida y ésta fue ella que entró en la carne del hombre creado, del hombre formado; ésta fue su sangre, de ésta se hizo la sangre del hombre. Así entró el maíz [en la formación del hombre] por obra de los Progenitores. [...] De maíz amarillo y de maíz blanco se hizo su carne; de masa de maíz se hicieron los brazos y las piernas del hombre. Únicamente masa de maíz entró en la carne de nuestros padres, los cuatro hombres que fueron creados. (RECINOS, 1960, p. 28-104)

$\mathrm{Na}$ versão do livro maia, os primeiros homens e mulheres foram criados respectivamente de terra, madeira e milho. Dessa forma, a distinção entre as histórias encontra-se na versão do Popol vuh, porém, no decorrer da história, encontramos semelhanças entre a versão maia e a que foi narrada pelo ancião. A reunião entre os deuses para a tomada de decisões coletivas e a criação do último homem, feito de milho (mais uma vez, a presença do alimento sagrado para os indígenas) revela trechos em comum entre ambas as histórias.

O uso de cosmologias indígenas é um recurso bastante explorado pelo subcomandante Marcos em suas construções narrativas. Com essa apropriação, o autor nos proporciona o conhecimento de histórias e informações que estão além do conhecimento tangível e racional, ou seja, dá acesso a um conhecimento que provém do imaginário dos grupos indígenas. Para a pesquisadora Aracy Lopes (SILVA, 1994, p. 75), cosmologias significam teorias do mundo, de como este funciona e como os sujeitos inseridos nele se manifestam e atuam. Segundo a cosmologia, os homens, os animais, a natureza e os deuses estão em constante contato e movimento, a fim de produzir e renovar a existência e vida nesse cenário. Uma das formas de expressar as cosmologias, entre os grupos indígenas, seria a utilização da linguagem, dos símbolos ou de ritos. O Velho Antônio, como a representação de um ancião indígena, produz a expressão das cosmologias da região chiapaneca a partir das histórias que são contadas a Marcos. Porém, deve-se atentar às modificações que essas histórias podem sofrer ao passo em que são transmitidas, transformações essas ocasionadas de forma eventual ou proposital.

Um dos aspectos mais recorrentes nas cosmologias indígenas é a presença dos mitos, que podem se apresentar de forma linear ou desconexa, dependendo das intenções que os

\section{GANPHLAC}

Revista Eletrônica da ANPHLAC, ISSN 1679-1061, Nº. 17, p. 189-213, jul./dez. 2014. http://revista.anphlac.org.br/ 
sujeitos que os consideram ou os narram pretendem aplicar. Para Levi-Strauss (1978, p. 3438), os mitos podem possuir diversas funções ao serem instrumentalizados pelas comunidades tradicionais, como, por exemplo, transmitir conhecimento aos seus descendentes a partir de um passado remoto, mas que, por sua vez, apresenta bases para um presente, ou até mesmo servir de reivindicação e legitimação de demandas políticas, assim tornando-se cosmologias políticas. Levi-Strauss (1978, p. 34-38) aponta ainda que é possível identificar o mito como um possível ponto de passagem à construção de uma história ou "outro tipo de história", não essencialmente aquela construída pelos historiadores, mas uma história que possui como núcleo uma base mitológica e que explica determinados contextos ou ordens sociais. Em suas palavras:

Como se vê, temos uma célula explicativa. A sua estrutura básica é a mesma, mas o conteúdo da célula já não é o mesmo e pode variar; é, portanto, uma espécie de minimito, se assim se pode dizer, porque é muito curto e muito condensado, mas tem ainda a propriedade de um mito, na medida em que o podemos seguir sob diferentes transformações. Quando se transforma um elemento, então os outros elementos têm de ser forçosamente readaptados às mudanças sofridas pelo primeiro. (LEVI-STRAUSS, 1978, p. 34-38)

As considerações acima nos levam a compreender o porquê da utilização do mito de criação do mundo no texto de Marcos. Em primeiro lugar, a associação com o Popol vuh é realizada com o intuito de promover a recuperação de um objeto representante da memória histórica coletiva dos povos indígenas da região chiapaneca (RIVERA ALMAGUER, 2001, p. 45), assim criando uma noção de reconhecimento e pertencimento. A referência aos deuses se faz com o objetivo de explicar a realidade a partir de histórias, principalmente através dos mitos. Dessa forma, os deuses maias que protagonizam o mito de criação do mundo nos apresentam a visão indígena desse acontecimento.

Ainda nesse mesmo documento, publicado no dia 28 de maio de 1994, o subcomandante Marcos inicia a narração de uma segunda história contada pelo Velho Antônio, que, por sua vez, recebe o mesmo nome apresentado no título do texto: Los arroyos cuando bajan. Nesse conto, o subcomandante relata um acontecimento vivenciado por ele cerca de dois anos antes da sublevação de 1994, quando visitava as comunidades indígenas com o intuito de acompanhar as discussões que elas realizavam em torno da questão do início do levante armado. Marcos conta que, ao chegar à comunidade à qual o Velho Antônio

\section{GANPHLAC}

Revista Eletrônica da ANPHLAC, ISSN 1679-1061, Nº. 17, p. 189-213, jul./dez. 2014.

http://revista.anphlac.org.br/ 
pertencia, foi chamado por ele para uma conversa sobre a situação que estava sendo vivenciada por todos. Afirma que o ancião o levou até um rio próximo à região e lhe disse:

\begin{abstract}
“¿Lo ves? Todo está tranquilo y claro, parece que no pasa nada...” "Mmmh”, le dije, sabiendo que no esperaba ni un sí ni un no. Después me señaló la punta de la montaña más cercana. Las nubes se acostaban, grises, en la cúspide y los relámpagos quebraban el azul difuso de las lomas. Una tormenta de las de deberás, pero se veía tan lejana e inofensiva que el viejo Antonio empezó a liar un cigarrillo y a buscar inútilmente un encendedor que no tenía, sólo el tiempo suficiente para que yo le acercara el mío. "Cuando todo está en calma abajo, en la montaña hay tormenta, los arroyos empiezan a tomar fuerza y toman rumbo hacía la cañada", dijo después de una bocanada. En la época de lluvias este río es fiero, un látigo marrón, un temblor fuera de cauce, es todo fuerza. No viene su poder de la lluvia que caen en sus riberas, son los arroyos que bajan de la montaña los que lo alimentan. Destruyendo, el río reconstruyen la tierra, sus aguas serán maíz, frijol y panela en las mesas de la selva. (EZLN, 1994, p. 243-245)
\end{abstract}

O que o Velho Antônio explica ao subcomandante é que os momentos de tormenta podem ser representados pela fúria das nuvens no topo das montanhas e que esse acontecimento gera reflexos na natureza, principalmente na dinâmica dos rios que estão abaixo dela. Na voz do ancião, as tormentas podem ser eventos, acontecimentos e desafios que estão ou serão enfrentados pelos indígenas zapatistas; os arroyos são as correntezas que irão desembocar no vale, ou seja, nas cañadas. Na definição que Antônio oferece a Marcos, os arroyos e as cañadas são, respectivamente, o braço armado do EZLN e as bases indígenas do movimento. Assim, quando o Velho Antônio conta a Marcos que "así es la lucha nuestra. [...] Ustedes son los arroyos y nosostros el río” (EZLN, 1994, p. 244), ele quer dizer que a luta dos zapatistas se faz a partir da união com os guerrilheiros que deram origem ao movimento e que essas forças devem se juntar para enfrentar aquele momento em questão.

A metáfora construída a partir da utilização de elementos da natureza é um recurso constante na escrita de Marcos. Elementos tais como a montanha, a noite, os rios, as estrelas, o sol e a lua são, por vezes, utilizados nos contos e histórias narrados pelo ancião. Além de um recurso do autor para explicar determinadas situações, esses elementos também estão presentes na visão de mundo indígena, nas cosmologias indígenas.

Para Isabelle Vidal (GIANNINI, 1994, p. 45), as cosmologias indígenas incluem os elementos da natureza como parte integrante da visão de mundo desses povos. Além disso, esses elementos podem interagir com a sociedade indígena e seus integrantes a partir da utilização de metáforas, cerimônias, símbolos e mitos, ou mesmo a partir de um contato real.

\title{
GANPHLAC
}

Revista Eletrônica da ANPHLAC, ISSN 1679-1061, No. 17, p. 189-213, jul./dez. 2014. http://revista.anphlac.org.br/ 
Intensificar a ideia de ligação e pertencimento dos grupos indígenas em relação à natureza circundante é possibilitar a crença de que ambos participam da constituição dos cosmos, ou seja, que estão inseridos em um único mundo em pleno desenvolvimento. Logo, a natureza e seus elementos fazem parte da vida societária desses grupos indígenas.

As duas histórias apresentadas ao longo dos parágrafos anteriores foram escritas pelo subcomandante Marcos e publicadas pelo CCRI-CG em 1994, no contexto de negociações que o EZLN desenvolvia com o governo e a sociedade civil mexicana. Entendemos essas publicações como expressão da etnicidade indígena zapatista, pois, numa relação interrelacional com os demais atores em questão, os zapatistas conseguiram se manifestar politicamente a partir da demonstração de alguns "sinais diacríticos" da identidade étnica apresentados nos contos e relatos do Velho Antônio.

O uso de metáforas que transbordam as cosmologias indígenas, em que os deuses primeiros falam da criação do mundo e dos homens, nos levam a pensar na criação de um novo mundo proposto pelos zapatistas. Esse novo mundo sugerido pode ser representado pela ideia de um novo México que reconheça as inúmeras identidades indígenas presentes no país. Quando os zapatistas iniciam os "Diálogos da Catedral” com o governo federal, apresentam propostas para o que esperam ser esse novo país; assim, o mito de criação exposto no conto do Velho Antônio representa essa analogia.

\section{Los zapatistas no se rinden}

Esses "Diálogos" representaram, no contexto histórico em questão, a primeira tentativa de negociação entre os membros do movimento e o governo federal mexicano. Seu resultado não se mostrou satisfatório para o EZLN e, dessa forma, foi representado nos documentos publicados pelo CCRI-CG nos meses seguintes. Entre eles, temos um comunicado que trouxe consigo mais uma produção discursiva de Marcos. Intitulado os zapatistas no se rinden (EZLN, 1994, p. 267-268), veio acompanhado, em sua parte final, de duas posdatas: a primeira, de autoria do CCRI-CG, e a segunda, do próprio subcomandante. Esta última nos interessa, pois nela há um relato de Marcos em que o Velho Antônio aparece.

O subcomandante tenta nos explicar o significado de "se render", ou rendir, relatando que, juntamente ao Comitê, ele e os demais membros discutiram por todo um dia seu sentido.

\section{GANPHLAC}

Revista Eletrônica da ANPHLAC, ISSN 1679-1061, N. 17, p. 189-213, jul./dez. 2014. http://revista.anphlac.org.br/ 
Logo após, sem nenhuma definição, descobriram que esta não tinha tradução na língua indígena, "no tiene traducción en tzotzil ni en tzeltal, nadie recuerda que esa palabra exista en tojolabal o en chol" (EZLN, 1994, p. 267-268). Sem respostas e aflito, Marcos relata que

El Viejo Antonio espera a que todos se vayan quedando calados y sólo quede el tambor de la lluvia sobre el techo de lámina. En silencio se me acerca el Viejo Antonio, tosiendo la tuberculosis, y me dice al oído: "Esa palabra no existe en la lengua verdadera, por eso los nuestros nunca si rinden y mejor se mueren, porque nuestros muertos que las palabras que no se andan no se vivan". (EZLN, 1994, p. 267-268)

A explicação dada pelo ancião indígena revela uma tentativa do subcomandante de representar o momento que estava sendo vivenciado pelo movimento zapatista: o posicionamento que reforçavam publicamente, a partir desse momento, em relação ao governo mexicano, ou seja, uma oposição política explícita. A frase que dá nome ao comunicado, "no se rinden", demonstra que os zapatistas não irão se render diante das situações a que forem ou serão expostos. O recurso de Marcos, que foi o de voltar a uma história contada pelo Velho Antônio para exemplificar esse momento, serviu para reforçar a ideia de que os indígenas zapatistas encontram suporte num passado de resistência histórica vivido por seus ancestrais.

Para Carla Valdespino, os relatos do Velho Antônio são "la segunda lectura dialógicatransculturada de un acontecimento" (VARGAS, 2009, p. 57), ou seja, a intenção do subcomandante Marcos seria esboçar um acontecimento vivenciado pelos zapatistas, a partir de uma visão de mundo indígena, por um conhecimento advindo do mundo indígena, levando assim os leitores a se familiarizar com alguns dos "sinais diacríticos" da identidade étnica indígena. Além disso, para a autora, o comunicado, além de apresentar uma noção de resistência histórica, também apresenta o resultado a que as comunidades indígenas que formam as bases do zapatismo chegaram após o resultado da Consulta Nacional, negando assim os "acordos" do governo. Dessa forma, esse comunicado seria uma sinédoque ${ }^{13}$ das consultas de bases ocorridas no interior dessas comunidades indígenas.

Apesar da pequena extensão do relato, este se tornou importante e afirmou uma postura que passaria a ser adotada pelos zapatistas nos meses e anos posteriores: a resistência contínua. Durante esse período, uma forma encontrada pelo EZLN para reunir ao movimento

\footnotetext{
${ }^{13}$ Figura de expressão que consiste em empregar o todo pela parte, ou vice-versa, do mais para o menos, ou viceversa.
}

\section{CANPHLAC}

Revista Eletrônica da ANPHLAC, ISSN 1679-1061, N. 17, p. 189-213, jul./dez. 2014. http://revista.anphlac.org.br/ 
as forças civis nacionais, a fim de discutir os aspectos concernentes à política mexicana, foi organizar uma reunião nacional denominada Convenção Nacional Democrática, que se realizaria entre os dias 5 e 9 de agosto de 1994, às vésperas das eleições presidenciais no país, iniciando-se em San Cristóbal de Las Casas e terminando na Selva Lacandona, no estado de Chiapas.

Podemos admitir que o maior desafio enfrentado pelos zapatistas na CND diz respeito aos impasses ocorridos no processo de deliberações e votação das propostas formuladas nos dias da reunião. Com cerca de 8 mil participantes, a tomada de decisões coletiva tornou-se um desafio para os zapatistas. Em entrevista a Guilherme Gitahy, o sociólogo Enrique de la Garza, participante do evento, definiu o momento da seguinte forma:

No primeiro dia, a discussão estava muito difícil, com os grupos trocando acusações e procurando controlar o encontro. Depois veio a ventania e a chuva, e para muitos não havia onde buscar proteção. Daí a lenda de que os deuses aplacaram assim o espírito maligno da esquerda. No dia seguinte, as discussões fluíram e foram feitas muitas negociações, o que parecia impossível no dia anterior. (FIGUEIREDO, 2006, p. 191)

O que o depoimento nos demonstra é a riqueza de representação civil presente no evento, representação esta que, em alguns momentos, mostrou-se conflituosa. Reunindo participantes das mais variadas tendências políticas e classes sociais, no primeiro e segundo dia, percebeu-se que ocorriam muitas discussões, porém sem finalizações. Nos meses posteriores, a CND se manteve como uma força política e social com atuação em diversos estados e municípios mexicanos, com integrantes advindos dos movimentos sociais camponeses e indígenas, movimentos estudantis, movimentos urbanos e partidários. Esse foi um momento de desenvolvimento de ideias e discussões sobre como a sociedade civil, juntamente com EZLN, iria se posicionar diante da política mexicana.

\section{La historia de la noche y las estrellas}

Em sua segunda edição, ocorrida em San Cristóbal de las Casas no dia 4 de novembro, os problemas relacionados às definições de ideias e de ações práticas continuaram permeando os membros da convenção e seu andamento. Porém, o que seria necessário fazer para que os participantes da CND chegassem a um acordo ou a vários acordos? O que essas pessoas poderiam aprender com os indígenas zapatistas sobre o processo de tomada de decisões

\section{GANPHLAC}

Revista Eletrônica da ANPHLAC, ISSN 1679-1061, No. 17, p. 189-213, jul./dez. 2014. http://revista.anphlac.org.br/ 
coletivas? Com o intuito de oferecer respostas a esses conflitos, o subcomandante Marcos publicou, no dia 6 de outubro de 1994, dias antes do segundo evento, um texto que representaria a situação. Intitulado La historia de la noche y las estrellas (EZLN, 1994, p. 8891), inicia o texto apresentando um diálogo que possivelmente manteve com o subcomandante Tacho, também porta-voz do EZLN e de origem indígena, em que este indicava a Marcos um problema que havia verificado nas últimas reuniões ocorridas no interior do grupo da CND. O texto diz:

Todos quieren dar órdenes pero nadie quiere obedecerlas. En la CND hay puros comandantes y deberían tener subcomandantes, mayores, capitanes, tenientes, milicianos, bases de apoyo. Pero todos quieren mandar sin obedecer. ¿Cómo van ofrecer algo nuevo al pueblo si hacen puras cosas viejas? (EZLN, 1994, p. 88-91)

Para responder à pergunta de Tacho, o subcomandante retoma um relato do Velho Antônio, em que o ancião conta a Marcos que, no início do mundo, todos os dias se resumiam em noite, tudo era noite. Os homens e mulheres que viviam nesse mundo sempre estavam tristes por conta do largo teto de sombras que os cobria. Com isso, os deuses sentiram-se tristes com a infelicidade dos homens e das mulheres e, então, se reuniram para tomar uma decisão sobre o que fazer para torná-los felizes, pois "los dioses siempre sacaban acuerdos para hacer los trabajos, y así aprendieron a hacer nuestros mayores y así aprendimos nosotros. A sacar acuerdo para hacer los trabajos aprendimos" (EZLN, 1994, p. 88-91). Depois de muito discutir, os deuses pensaram em acabar com o teto de sombras que cobria os homens e mulheres para permitir que a luz solar os iluminasse e, assim, ficassem felizes. Porém, eles não sabiam que a luz do sol era forte e que cegaria os homens e mulheres, impedindo-os de enxergar e trabalhar. Diante do problema, os deuses perceberam que haviam errado e machucado os homens e mulheres, por isso "se reunieron otra vez y sacaron nuevo acuerdo de poner otra vez el largo techo de la noche mientras pensaban bien como hacer un buen acuerdo" (EZLN, 1994, p. 88-91).

Na sequência do relato, o Velho Antônio conta que, enquanto os deuses resolviam se esta era realmente uma boa decisão, homens e mulheres aprenderam como caminhar sobre a noite, sem luz. Como os deuses demoraram a resolver, tiveram que aprender a sobreviver e, depois de muito tempo, receberam a notícia de que precisariam de ajuda para que solucionar de vez o problema. A solução viria a partir da ajuda de voluntários para salpicar o céu escuro

\section{GANPHLAC}

Revista Eletrônica da ANPHLAC, ISSN 1679-1061, N. 17, p. 189-213, jul./dez. 2014. http://revista.anphlac.org.br/ 
de luz, ou seja, esses voluntários seriam estrelas iluminando o céu. Dessa forma, a situação se converteu:

[...] todos los hombres y mujeres dijeron que eran voluntarios porque todos querían ser estrellas y ya no querían ser hombres y mujeres murciélago, y todos y todas se hicieron estrellas y lo hoyaron todo el techo de la larga noche y ya no quedó ni un pedacito bueno del techo de la noche y todo era otra vez pura luz y la problema no se terminaba y era peor porque ya se había roto todo el techo de la noche y ya no había como tapar la luz que caía por todos los lados. Y los dioses ya no se dieron cuenta porque estaban dormidos muy contentos que ya lo habían resuelto la problema y no tenían pena y por eso se durmieron. (EZLN, 1994, p. 88-91)

A metáfora exposta no relato esboça o conflito que estavam vivenciando os zapatistas junto à sociedade civil na CND. Da mesma forma como homens e mulheres brigavam entre si para serem estrelas brilhantes no céu escuro, os participantes da convenção discutiam arduamente sobre as deliberações que deveriam acontecer no encontro. Assim, mais uma vez, a partir do Velho Antônio, o escritor Marcos consegue mostrar ao mundo um aspecto do mundo indígena que envolve os deuses e as cosmologias para exemplificar um evento presente naquele momento.

Além desse aspecto, um ponto importante a ser observado neste momento é a importância e o significado que assume a noite nesse relato. Não somente nessa, mas também em outras histórias, a noite assume presença, como palco e cenário. ${ }^{14}$ Para Bellinghausen, a noite é quando o Velho Antônio aparece para Marcos, fuma e conta as histórias. É quando os deuses aparecem, conversam e fazem acordos (BELLINGHAUSEN apud VARGAS, 2009, p. 108). Também, como propõe Domínguez, a noite é o espaço do qual emerge a luz, no dia seguinte. E, com a luz que nasce da noite, temos a criação do novo, do novo dia, do novo mundo (DOMÍNGUEZ apud VARGAS, 2009, p. 78).

Com essas considerações, podemos apontar que a noite assume importância simbólica nos textos em que o Velho Antônio narra, pois a intenção é demonstrar que ela possibilita, em seu percurso, a gestação daquilo que nascerá posteriormente, com o nascer da luz. Assim, os zapatistas propõem, em seus inúmeros comunicados, quando falam que desejam um México com uma nova política e democracia, um país que se desprenda dos velhos e arcaicos padrões

${ }^{14}$ Em La historia de la noche e em La historia del aire de la noche, por exemplo.

\section{GANPHLAC}

Revista Eletrônica da ANPHLAC, ISSN 1679-1061, Nº 17, p. 189-213, jul./dez. 2014. http://revista.anphlac.org.br/ 
políticos partidaristas e corruptos e assuma uma força advinda do povo mexicano, um povo que possa participar e fazer funcionar. Para fortalecer nossa afirmação, temos o que nos diz Carla Valdespino sobre a presença desse elemento nos contos do Velho Antônio:

La importancia de la noche radica en varios aspectos. En primer lugar, por el espacio donde Marcos y el Viejo Antonio se encuentran para contar y escuchar las historias de los dioses. La noche es, sobre todo, la alegoría de la esperanza de un mundo nuevo, pues fue creada para que cosas buenas sucedieran en ellas. En la noche se forja la luz del amanecer, cuya luz será para todos aquellos que se les ha negado el día, la vida. La noche es la esperanza. En la noche se crea un nuevo mundo. (VARGAS, 2009, p. 113-114)

No finalizar do relato, percebemos que, para solucionar o problema no qual estavam envolvidos, homens e mulheres reuniram-se e realizaram uma assembleia, como faziam os deuses, para pensar e decidir. Chegaram à conclusão de que era necessário que algumas estrelas se apagassem para que outras pudessem brilhar e iluminar o céu adequadamente, com a proporção de luz correta. Porém, antes do veredito, perceberam que havia alguns entre eles que não queriam se apagar de jeito algum. Nesse momento, os homens e as mulheres que tinham a cor da terra - pois o milho vem da terra -, os homens feitos de milho e de coração verdadeiro decidiram se apagar para que houvesse luz adequada sem prejudicar os demais. Dessa forma, o problema estava solucionado; quando os deuses acordaram, depararam-se com a noite sendo iluminada por estrelas, com homens e mulheres vivendo bem entre si. Achavam os deuses que eles haviam resolvido o problema, porém não imaginavam que os homens e mulheres de milho é que o haviam feito. Assim, a história do Velho Antônio nos revela que "algunos tienen que estar apagados para que brillen otros, pero los que brillan la hacen por los apagados. Que si no, pues nadie brilla”. (EZLN, 1994, p. 88-90)

\section{Considerações finais}

Com este artigo, tentamos demonstrar a importância discursiva e literária assumida pela criação textual do subcomandante insurgente Marcos, membro político e militar do EZLN, principalmente no decorrer das publicações realizadas no ano de 1994. Para isso, realizamos a análise de histórias e contos escritos pelo autor que evidenciaram algumas de suas principais habilidades e funções.

\section{GANPHLAC}

Revista Eletrônica da ANPHLAC, ISSN 1679-1061, No. 17, p. 189-213, jul./dez. 2014. http://revista.anphlac.org.br/ 
Podemos afirmar que a criação literária do subcomandante Marcos tornou-se importante para o movimento zapatista, pois, além de completar os discursos dos rebeldes, em diversas ocasiões, também se tornou voz discursiva, representando-os.

Percebemos que as histórias analisadas foram produzidas em contextos históricos inter-relacionais vivenciados pelos zapatistas, seja com o governo, seja com a sociedade civil mexicana. Tendo em vista essa informação, vimos que a produção literária do subcomandante buscou, nesses momentos, apontar elementos ou "sinais" que representassem os grupos indígenas que compõem o movimento zapatista. A partir da criação do ancião Velho Antônio, em suas histórias, Marcos conseguiu levar ao leitor que vivenciava os acontecimentos informações sobre o passado e a memória dos indígenas chiapanecos. Dessa ação, acreditamos ter ganhado importância a escrita de Marcos, pois ela não assumiu caráter meramente ficcional ou literário, mas também funções políticas, na medida em que tentou representar esses grupos étnicos em seus escritos.

Devemos levar em consideração, também, que o protagonismo literário assumido por Marcos merece ser analisado em conjunto com as circunstâncias históricas que o levaram a assumir esse lugar. Também devemos ter em mente que as histórias escritas pelo membro militar do movimento pode ter encontrado espaços de críticas e resistências nas estruturas e composições internas do movimento. Porém, essas questões demandariam análises e investigações mais profundas.

Nosso objetivo direcionou-se para o subcomandante Marcos enquanto autor, caracterizando e analisando suas produções. Além disso, demonstramos que ele assumiu, sim, importância vital nas produções discursivas do EZLN, a partir de suas criações literárias, legitimando os grupos indígenas zapatistas desde o levante armado de 1994 no México. Esta foi sua principal contribuição política para os zapatistas.

\section{GANPHLAC}

Revista Eletrônica da ANPHLAC, ISSN 1679-1061, №. 17, p. 189-213, jul./dez. 2014.

http://revista.anphlac.org.br/ 


\section{Referências documentais e bibliográficas}

\section{Documentais}

EZLN. Documentos y comunicados. "Los arroyos cuando bajan". Tomo 1. México: ERA, 1994.

EZLN. Documentos y comunicados. "Los zapatistas no se rinden”. Tomo 1. México: ERA, 1994.

EZLN. Documentos y comunicados. "Resultado de la consulta". Tomo 1. México: ERA, 1994.

\section{Bibliográficas}

ALBERTO BARTOLOMÉ, Miguel. Gente de costumbre y gente de razón: las identidades étnicas en México. México: Siglo Veintiuno Editores, 2010.

BARTRA, Armando. Mitos en la aldea global. In: MARCOS, Subcomandante Insurgente. Relatos del el Viejo Antonio. San Cristóbal de Las Casas: CIACH, 1998.

BERGHE, Kristine Vanden. Narrativa de la rebelión zapatista: los relatos del subcomandante Marcos. Vervuert: Iberoamericana, 2005.

CARDOSO, Ciro Flamarion; VAINFAS, Ronaldo. Domínios da história: ensaios de teoria e metodologia. Rio de Janeiro: Elsevier, 1997.

CASTELLS, Manuel. $O$ poder da identidade. A era da informação: economia, sociedade e cultura. Tradução de Alexandra Lemos e Rita Espanha. Vol. 2. Lisboa: Fundação Calouste Gulbenkian, 2003.

CUNHA, Manuela Carneiro da. Antropologia do Brasil: mito, história e etnicidade. São Paulo: Edusp, 1986.

DE LA GRANGE, Betrand; RICO, Maite. Marcos: la ingenial impostura. México: Nuevo Siglo Aguilar, 1997.

DEBRAY, Régis. A demain Zapata, Le Monde, Paris, maio, 1995.

FOUCAULT, Michel. O que é um autor? Bulletin de la Societé Française de Philosophie, $63^{\circ}$ ano, n. 3, julho-setembro de 1969.

FUENTES SÁNCHEZ, Waldo Lao. Autonomia zapatista: o projeto de integração dos movimentos latino-americanos a partir de baixo e junto com os de fora. 2012. Dissertação (Mestrado) - Universidade de São Paulo, São Paulo, 2012.

\section{GANPHLAC}

Revista Eletrônica da ANPHLAC, ISSN 1679-1061, N. 17, p. 189-213, jul./dez. 2014.

http://revista.anphlac.org.br/ 
GIANNINI, Isabelle Vidal. Os índios e suas relações com a natureza. In: BENZI, Luís Donisete (Org.). Índios no Brasil. Brasil: Ministério da Educação e do Desporto, 1994.

IÑIGUEZ, Lupicinio. Prática da análise do discurso. In: IÑIGUEZ, Lupicinio (Coord.). Manual de análise do discurso em ciências sociais. Tradução de Vera Lúcia Joscelyne. Petrópolis: Vozes, 2004.

LANGFIELD, Martin. Los zapatistas ganan la guerra del ciberespacio. Página 12, 15 dez 1995.

LE BOT, Yvon. O sonho zapatista. Portugal: Edições Asa, 1997.

LEVI-STRAUSS, Claude. Mito e significado. São Paulo: Coletivo Sabotagem: 1978.

OLIVEIRA, Roberto Cardoso de. Identidade, etnia e estrutura social. São Paulo: Pioneira, 1976.

ORTIZ, Pedro; BRIGE, Marco; FERRARI, Rogério. Zapatistas: a velocidade do sonho. Brasília: Entrelivros - Thesaurus, 2006.

PELLICER, Juan. La gravedad y la gracia: el discurso del subcomandante Marcos. Revista Iberoamericana, v. LXII, n. 174, enero-marzo, 1996.

PINTO, Milton José. Comunicação e discurso. $2^{\mathrm{a}}$ ed. São Paulo: Hacker Editores, 2002.

POUTIGNAT, Phlippe; STREIFF-FENART, Jocelyne. Teorias da etnicidade: seguido de grupos étnicos e suas fronteiras de Fredrik Barth. Tradução Elcio Fernades. $2^{\mathrm{a}}$ ed. São Paulo: Unesp, 2001.

RECINOS, Adrián. Popol Vuh. Las antiguas historias del Quinché. Traducidas del texto original con introducción y notas. México: Fondo de Cultura Económica, 1960.

RIVERA ALMAGUER, Raquel Xochiquetzal. El Libro del Popol Wuj como lugar de memoria y su influencia en la política cultural del movimiento maya en Guatemala. $5^{\circ}$ Congreso regional de Historia y Historiografia, 2001.

SILVA, Aracy Lopes da. Mitos e cosmologias indígenas no Brasil: breve introdução. In: BENZI, Luís Donisete (Org.). Índios no Brasil. Brasil: Ministério da Educação e do Desporto, 1994.

VOS, Jan de. Una tierra para sembrar sueños. Historia reciente de la Selva Lacandona (1950-2000). México: FCE, CIESAS, 2002.

\section{GANPHLAC}

Revista Eletrônica da ANPHLAC, ISSN 1679-1061, N. 17, p. 189-213, jul./dez. 2014.

http://revista.anphlac.org.br/ 